\title{
Nietzsche, filho de seu tempo: a questão do ascetismo*
}

\author{
Bertrand Binoche ${ }^{* *}$
}

Resumo: o presente artigo tem por objetivo examinar de que forma o contexto histórico-filosófico do século XIX influenciou a compreensão nietzschiana acerca do ascetismo. Para tanto, foi necessário se afastar da obra de Nietzsche e levar a cabo uma pesquisa de ordem filológica em textos filosóficos que tratavam do tema no referido século, a qual trouxe à baila a hipótese de que o termo "ascetismo" - apesar de possuir raízes doutrinárias, conceituais e etimológicas na antiguidade e na idade média - surge nos textos da filosofia europeia apenas no século XIX. Ao longo da argumentação também se evidencia como a interpretação e o uso utilitarista da noção de ascetismo foi essencial para a elaboração da crítica nietzschiana ao ideal e às práticas ascéticas.

Palavras-chave: ascetismo, século XIX, utilitarismo, Schopenhauer, Bentham.

\footnotetext{
* Tradução: João Evangelista Tude de Melo Neto.

** Professor na Université Paris-I/Panthéon-Sorbonne, Paris, França.

Correio eletrônico: bertrand.binoche@univ-parisl.fr
} 
Binoche, B.

Não é preciso ter tido muito contato com a obra de Nietzsche para saber que a questão do ascetismo ocupou bastante as reflexões do filósofo, pois constitui um dos grandes leitmotiven de um corpus no qual ela pode ser bem localizada. A questão situa-se entre dois limites muito claros. Um deles é Humano, demasiado humano (1878), no qual é tratada num conjunto de parágrafos que vai do $§ 136$ ao $\S$ 144. O outro, obviamente, é a terceira dissertação de Genealogia da moral (1887), na qual a questão é tratada com amplitude inédita naturalmente, encontrar-se-á ecos do tema, em 1888, no Crepúsculo dos ídolos ("Moral, como antinatureza") e no Anticristo (especialmente os parágrafos § 20-22 e 51). No intervalo entre Humano, demasiado humano e Genealogia da moral, o ascetismo aparece como um enigma decisivo, uma vez que Nietzsche trata do assunto sem cessar em Aurora, A gaia ciência, Zaratustra e Além do bem e do mal.

As páginas que se seguem pretendem transformar a simples constatação do interesse de Nietzsche pelo ascetismo em uma questão falsamente ingênua: por que então Nietzsche é tão interessado pelo "ascetismo"? Afinal de contas, não se trata de um problema banal na tradição filosófica: Aristóteles, Descartes ou mesmo Hume não falam do "ascetismo".

Ora, essa questão tem duas facetas.

Claro, pode-se e deve-se respondê-la de um modo interno perguntando-se: qual é o sentido crucial que Nietzsche conferiu ao ascetismo? A crítica permanece a mesma de 1878 a 1887? Que lugar essa crítica ocupa na Genealogia? E qual é exatamente a genealogia que ele realiza acerca do tema? Indo nessa direção, deve-se chegar a uma leitura escrupulosa da terceira dissertação da Genealogia $d a$ moral. Werner Stegmaier se ocupou dessa tarefa em 1994 com muito rigor. ${ }^{1}$ É claro que é possível não concordar completamente com sua análise, mas o fato é que o trabalho já foi realizado, e bem realizado.

1 Werner Stegmaier, 155994, cap. 7. Podemos também mencionar o capítulo 5 da obra de Lawrence J. Hattab, 2008, ou o comentário de Daniel Conway, 2008, p.100-153.

12 | Cad. Nietzsche, Guarulhos/Porto Seguro, v.39, n.2, p. 11-26, maio/agosto, 2018. 
Nietzsche, filho de seu tempo: a questão do ascetismo

Todavia, ao abordarmos o problema dessa maneira, cometemos a falácia da petição de princípio, visto que se toma por dado algo que é, na verdade, uma dificuldade. Pois, supõe-se a questão do ascetismo como autoevidente e que, portanto, apenas a resposta é importante. Presume-se que se trata de uma questão própria de Nietzsche: Nietzsche colocou para si a questão do ascetismo - e, então, pergunta-se como ele a solucionou. Como se ele tivesse criado tudo a partir do zero. O que, aliás, parece ser algo mínimo para um gênio "inatual".

A questão "por que Nietzsche se interessou tanto pelo ascetismo?" deve, portanto, ser colocada, ainda, dessa maneira: de onde ela lhe veio? Pois Nietzsche talvez tenha sido mais filho de seu tempo do que ele mesmo supunha. Ele mesmo chega, aliás, a desconfiar disso: “[...] aquilo que me parecia reservado, toda a época o persegue [...]" (Nachlass/FP 1885-1886, 2 [183], KSA 12.157). Isso é sobretudo verdadeiro no que diz respeito à questão ascética.

Antes, portanto, de compreender como Nietzsche tratou a questão ascética, é o caso aqui de perguntar-se o que o conduziu talvez o coagiu - a ela: por que o problema se impôs a ele? E a resposta proposta será a seguinte: a genealogia do ideal ascético fez com que Nietzsche ficasse cego no que concerne à história do conceito de ascetismo. Para sustentar essa hipótese, será necessário se afastar do próprio Nietzsche, correndo o risco de parecer esquecê-lo. Mas isso será para melhor retornar a ele e com a convicção de que não podemos ler um autor, seja ele quem for, se não nos desviarmos dele ao longo do caminho: não poderíamos compreender, desta forma, a máxima segundo a qual "cada um é para si próprio o mais distante" (FW/GC, 335, KSA 3.560)?

Nós propomos, portanto, o seguinte problema: se Nietzsche não inventou o conceito de ascetismo, de onde ele lhe veio, então? 
Binoche, B.

\section{Schopenhauer - O Pessimismo}

É evidente que pensamos imediatamente em Schopenhauer. Todo leitor de Nietzsche sabe que este filósofo está sempre por perto, mas isso é particularmente verdadeiro quando se trata do ascetismo, pela boa razão de que o ascetismo é especialmente importante para Schopenhauer.

Acima, foi dito que a crítica nietzschiana ao ascetismo foi iniciada em 1878, em Humano, demasiado humano. Isto é, ela aparece como uma consequência da ruptura com Schopenhauer e Wagner ${ }^{2}$. Não parece - sujeito à verificação - que encontremos traços notáveis dela, antes desse momento: é certo que, na terceira Extemporânea (1874), Nietzsche evoca, se referindo a Schopenhauer, a negação hindu do querer-viver (SE/Co Ext III., 3, KSA 1.350)ou seja, uma forma severa de ascetismo -, mas essa referência é positiva, e aparece como o objeto de uma nostalgia a qual atesta a genialidade do mestre ${ }^{3}$. Parece, portanto, razoável concluirmos isso: tomando distância de Wagner, Nietzsche se afasta simultaneamente de Schopenhauer, a grande referência daquele; e tomando distanciamento de Schopenhauer, ele se afasta da promoção schopenhauriana de ascetismo.

O ponto decisivo é efetivamente o seguinte: a filosofia de Schopenhauer havia conferido ao ascetismo um estatuto realmente remarcável, cuja expressão mais notável figura no suplemento 48 de Mundo como vontade e representação:

Mas nenhuma filosofia [...] tem o direito de ficar em silêncio em relação ao tema do quietismo e do ascetismo [das Thema des Quietismus und Asketismus] pois ele é, em substância, idêntico àquele de toda metafísica

2 Cf: Paolo D'Torio, 2012.

3 Conferir também a correspondência dos anos 67-68 (Carta para Carl von Gersdorff do dia 24 de novembro e 1 de dezembro de 1867, KSB 1.240, e carta para Paul Deussen do dia 22 de junho de 1868, KSB 1.290, onde o termo grego é explicitamente empregado).

14 | Cad. Nietzsche, Guarulhos/Porto Seguro, v.39, n.2, p. 11-26, maio/agosto, 2018. 
Nietzsche, filho de seu tempo: a questão do ascetismo

e de toda moral. Trata-se então de um tema acerca do qual eu espero e cobro de todas as filosofias, com o otimismo delas, um pronunciamento. ${ }^{4}$

Essa declaração esmagadora exige duas observações importantes:

(1) o ascetismo não é apenas apresentado, aqui, como o centro de gravidade da moral, mas também como o da própria metafísica. Ele está associado ao quietismo, o qual foi definido mais acima como "a renúncia de todas as vontades", ao passo que o ascetismo é "a mortificação premeditada da própria vontade". Do ascetismo, vai-se ao quietismo e do quietismo, vai-se ao misticismo, isto é, chega-se à "consciência da identidade de seu próprio ser com aquele de todas as coisas". Para quem conhece um pouco de Schopenhauer, isso se explica facilmente: querer é viver, e viver é sofrer - nesse sentido, para não sofrer, é preciso cessar de querer, negar a vida em vez de afirmá-la de maneira tola como um animal. $\mathrm{O}$ ascetismo é a negação salutar do querer-viver. E só podemos compreender isso se formos além da simples moralidade da piedade, abolindo afetivamente o princípio da individuação, para, assim, acessar seus fundamentos metafísicos: o querer-viver, o mundo como vontade.

Deve-se notar que dessa forma Schopenhauer faz das práticas mais rigorosas da penitência (o ascetismo) o preâmbulo de um estado espiritual (a contemplação quietista) o qual consiste em "não querer nada". Com efeito, Fénelon concebeu o "caminho purgativo" como tendo o propósito de conduzir ao "caminho unitivo ou contemplativo" via o "caminho iluminado"6. Mas deve-se notar que, na esteira de Molinos, ele tendeu a desvalorizar "a mortificação exterior dos sentidos" em favor da contemplação mística e é precisamente neste

4. Schopenhauer, 1966, p.1384-1385 (Tradução modificada).

5 Schopenhauer, 1966, p.1382.

6Fénelon, 2006, p.52-53.

Cad. Nietzsche, Guarulhos/Porto Seguro, v.39, n.2, p. 11-26, maio/agosto, 2018. 
Binoche, B.

afastamento que ele poderia declarar a grande máxima que constitui o leitmotiv de seus escritos espirituais:

Mas também, por outro lado, não é de modo algum a multiplicidade de visões nem de práticas duras, como também não é de modo algum o constrangimento e a contenção que promovem o verdadeiro avanço. Pelo contrário, é apenas uma questão de não querer nada e de querer tudo sem restrição e sem escolha, de ir alegremente sem preocupação, como a providência nos leva, de não buscar nada, de nada desencorajar, de encontrar tudo no momento presente $[\ldots]^{7}$.

Não é, evidentemente, um acaso que a ortodoxia católica, na pessoa de Bossuet, tenha vivamente reagido de forma negativa aos dois pontos colocados em questão pelo que ele pejorativamente chamou de "o novo misticismo". Por um lado, a necessidade irredutível da penitência não deveria ser minimizada: “Uma das piores características do quietismo é a de ter enfraquecido o remédio frequentemente necessário da mortificação [...]"8. Por outro lado, é insustentável pretender atingir nesta vida um estado no qual poderse-ia nada querer já que "é um mal evidente não querer de modo algum, de não pedir, de não render graças, de não agir de nenhum modo, de esperar que Deus nos impulsione" 9 . O verdadeiro cristão deve querer, pois ele deve querer sua salvação.

(2) A segunda observação concernindo a essa declaração de Schopenhauer decorre da primeira. A questão do ascetismo se transforma assim na pedra de toque de toda filosofia e se faz objeto de um verdadeiro desafio: quem, portanto, poderá compreender a tradição ascética melhor que o filósofo do querer-viver? Quem será capaz de melhor explicar sua antiguidade e extensão? A filosofia

7Fénelon, 1983, p.573 (destaque do autor).

8 Bossuet, 1697, p.405.

9 Bossuet, 1697, livre X, § 2, p.381. Sobre a permutação "nada/tudo querer" a qual não pode passar sem chamar a atenção do leitor de Schopenhauer e de Nietzsche, e acerca da qual voltaremos a tratar mais tarde, conferir Denise Leduc-Fayette, 1996, p.82-89.

16 | Cad. Nietzsche, Guarulhos/Porto Seguro, v.39, n.2, p. 11-26, maio/agosto, 2018. 
Nietzsche, filho de seu tempo: a questão do ascetismo

do Mundo apresenta-se triunfalmente como a primeira capaz de explicitar a significação metafísica do ascetismo. Sem dúvida tem sido praticado há milhares de anos. As grandes religiões (em primeiro lugar, o cristianismo, pelo menos o cristianismo "verdadeiro e primitivo" e o bramanismo ${ }^{10}$ ) já tinham compreendido muito bem, de maneira não teórica, mítica, que a salvação só poderia ser encontrada no esgotamento, em si, da vontade-de-viver. É por isso que elas inventaram fábulas - a começar pela noção de pecado original - cuja moral consiste em expressar a ideia de que a existência é intrinsecamente má, corrupta. E é por isso que eles criaram o que poderíamos chamar de artes de existir o mínimo possível - artes, no fundo, do inexistir, das quais o quietismo de Madame Guyon é uma das mais notáveis ilustrações, já que ensina desfazer-se, em linguagem schopenhauriana, de toda vontade própria, uma vez que ele ensina a livrar-se em si de qualquer forma de vontade, da vontade de vida - der Wille zum Leben.

Devemos, portanto, atribuir toda importância ao fato de que Nietzsche precisamente aceita o desafio e toma Schopenhauer pela palavra: a genealogia vai interpretar de uma maneira completamente diferente a valorização religiosa do ascetismo. Isto é, vai entendê-la como desvalorização triunfante da vida, a qual, a partir de agora, é redefinida como vontade de potência - der Wille zur Macht. Esse procedimento consiste abertamente na negação da negação do querer-viver, se nos é permitido o uso dessa terminologia dialética. Todavia, esse gesto não conduz a nenhuma espécie de reconciliação [Versöhnung]: ao contrário, ele é preferível justamente porque afirma a natureza irremediavelmente agonística da existência.

A formulação que orienta a terceira dissertação de Genealogia da moral e que a respeito da vontade afirma duplamente que esta "prefere antes querer o nada do que nada querer" e que "O homem

10 Contudo, não o Islamismo, "a pior e a mais recentes de todas as religiões" Schopenhauer, 1966, p. 1373.

Cad. Nietzsche, Guarulhos/Porto Seguro, v.39, n.2, p. 11-26, maio/agosto, 2018. | 17 
Binoche, B.

prefere ainda o nada do que nada querer" (GM/GM, III, 1, KSA 5.339), deve ser, portanto, compreendida sob duas perspectivas. De fato, "querer o nada" se opõe, por um lado, a "não querer nada", o imperativo schopenhauriano ao qual é, a bem da verdade, impossível satisfazer, pois a vontade não pode não querer. Isto seria a sua própria destruição. Contudo, "querer o nada" se opõe também a "querer tudo" (amor fati), o imperativo nietzschiano cujo eterno retorno é a enunciação eufórica.

Podemos então arriscar a seguinte hipótese interpretativa: a aliança operada por Fénelon é metamorfoseada historicamente em uma alternativa dual da qual Schopenhauer e Nietzsche figuram como os dois termos. A dupla injunção quietista - nada querer $e$ querer tudo, isto é, não querer nada em nome próprio, pois quer-se tudo o que quer Deus - dá lugar a uma disjunção: não querer nada ou querer tudo. Schopenhauer retém a primeira fórmula (que se transforma em não querer mais nada) e Nietzsche a segunda (que se transforma em querer que tudo retorne eternamente de forma idêntica). Evidentemente, Fénelon não será encontrado nem em um nem em outro!

Independentemente do partido que se possa tomar acerca dessa hipótese interpretativa que poderia talvez esclarecer a relação de Nietzsche com a tradição mística vamos nos ater, neste momento, apenas a algo que parece difícil de contestar, a saber: Nietzsche não poderia se afastar de Schopenhauer sem eleger como alvo o ascetismo que, pela primeira vez na história da filosofia, foi elaborado pelo próprio Schopenhauer. Através de Schopenhauer, com efeito, é todo o cristianismo derivado de São Paulo que se encontra, indiretamente, colocado em questão. E, no mesmo sentido, através do cristianismo, ainda o platonismo que consiste em seu protótipo esotérico ${ }^{11}$.

Nós reencontramos assim a vertente mais conhecida da genealogia - para dizer a verdade, nós nunca a deixamos! Mas

11 JGB/BM, "Prefácio", KSA 5.11.

18 | Cad. Nietzsche, Guarulhos/Porto Seguro, v.39, n.2, p. 11-26, maio/agosto, 2018. 
Nietzsche, filho de seu tempo: a questão do ascetismo

não podemos parar por aqui sem perdermos o essencial e, por isso, devemos retroceder um passo: Nietzsche deve a Schopenhauer a estrondosa promoção do ascetismo - mas e quanto a Schopenhauer, de quem ele é devedor?

\section{Bentham - O utilitarismo}

Essa questão apenas se constitui como fecunda, se a colocamos corretamente: de onde provém para Schopenhauer o conceito mesmo de "ascetismo"?

O leitor poderá julgar a questão redundante, uma vez que, aparentemente, ela já foi respondida indiretamente, quando evocamos Platão e São Paulo: o ascetismo chega a Schopenhauer por intermédio do pensamento grego e do conceito de askesis do qual podemos rastrear os vestígios. Frequentemente, a noção de askesis se refere às restrições às quais o atleta se impõe para triunfar nos jogos, na Epístola aos coríntios (IX, 24-27) ela se transforma, contudo, na disciplina por meio da qual o corpo é reduzido à escravidão. Daí, é possível, sem dúvida, seguir, passo a passo, o desenvolvimento da noção até chegarmos ao Mundo como vontade e representação.

Mas essa resposta se choca com uma objeção filológica desconcertante: podemos, sem dúvida, encontrar em francês os termos "ascète" [asceta] (atestado sob a forma "aschète" em 1580) e "ascétique" [ascético] (atestado primeiramente como substantivo em 1641). Da mesma maneira, em alemão, encontramos Ascetik, Ascet ou Asket, muito anteriormente a Schopenhauer. Todavia, em francês, o termo utilizado para traduzir askêsis é "exercício": assim acontece, por exemplo, no best-seller que foi a Introdução à vida devota de São Francisco de Sales (1609). Na mesma direção, utilizamos esse termo ainda hoje para traduzir, por exemplo, Epiteto. Um "asceta", na língua francesa clássica, é um "exercitante"12. Para designar as

12 Conferir o abade Claude Fleury, Les mœurs des chrétiens, Paris, 1682, cap. 21, p.152: o autor evoca 
Binoche, B.

práticas ascéticas cristãs mais severas, aquelas das quais tratarão Schopenhauer e Nietzsche, fala-se de "penitência", de "mortificação" ou de "austeridade". "Asceta" parece estar reservado à linguagem dos teólogos, os quais, aliás, utilizam o termo raramente, evocando os Padres do deserto sob o nome de "solitários". Em suma, askesis se traduz por "exercício" (físico ou espiritual) e não por "ascetismo". Pierre Hadot, aliás, chama atenção ao fato de que é necessário compreender a askesis grega "não como ascetismo, mas como prática de exercícios espirituais" $"$.

Essas considerações podem parecer tediosas e sem grande interesse. Contudo, o ponto ao qual convém atrair atenção é o seguinte: em todo esse contexto, há referências (muito raramente) a asceta ou a ascético, (muito frequentemente) a exercício ou a mortificação... mas nunca encontramos "ascetismo". Muito curiosamente, e sob-reservas de verificações filológicas que ainda precisam ser realizadas, parece que o termo "ascetismo", em francês, faz sua aparição somente no século XIX. A ocorrência mais antiga que eu pude encontrar, pelo menos até este momento, encontra-se na tradução de Bentham feita por Dumont em 1802: o segundo capítulo de Tratados de legislação civil e penal intitula-se "Princípio do ascetismo"14. Objetar-se-á, com justeza, que Nietzsche escreve em alemão, não em francês! Entretanto, precisamente, em alemão, há uma estranha coincidência, visto que o Deutsches Fremdwörterbuch não fornece nenhuma ocorrência, anterior a 1803, para "Asketismus"15, ou seja, o termo empregado por Schopenhauer no texto citado acima. No que concerne ao inglês, podemos então fazer referência ao texto original de Bentham e, com isso, remontarmos a 1789: o segundo capítulo de l'Introduction

\footnotetext{
"cristãos que praticavam voluntariamente todos os exercícios da penitência sem serem obrigados a isto, [...] castigando seus corpos para reduzi-los à servidão" e completa: "eles são chamados de ascetas, ou seja, exercitantes".
}

13 Pierre Hadot, 2002, p.21 (ver também p.77-78).

14 Portanto, esse registro é anterior à citação de Nodier (1818), fornecida por diversos dicionários.

15 É, aliás, a palavra que é utilizada em 1833 para traduzir para o alemão o mesmo texto de Bentham.

$20 \mid$ Cad. Nietzsche, Guarulhos/Porto Seguro, v.39, n.2, p. 11-26, maio/agosto, 2018. 
Nietzsche, filho de seu tempo: a questão do ascetismo

to the Principles of Morals and Legislation (1789) menciona de fato o "principle of asceticism" como contrário ao princípio de utilidade. O Oxford English Dictionary faz referência a uma ocorrência de "asceticism" em 1646; mas nada a respeito de "ascetism" antes de 1850. No que concerne ao italiano, ao espanhol, ao português, resta realizar a investigação.

Parece, portanto, que o ascetismo/Asketismus/ascetism, enquanto palavra, surge muito mais tarde do que seria de esperar. E pode-se lançar então razoavelmente a hipótese de que, como sempre, a aparição do significante seja em si significativo, indicando a aparição de um problema. O fato de que o termo "ascetismo" pareça se instalar tão tardiamente tanto na língua corrente como na língua filosófica (francesa e alemã) pode razoavelmente sugerir que algo de especial aconteceu, algo que diz respeito menos à aparição mesma do significante, do que ao seu sucesso. Pois esta palavra fixa-se, se enraíza e se propaga até Nietzsche que faz dela um dos seus alvos prediletos.

Nós devemos então perguntar: que significa a aparição terminológica do "ascetismo" stricto sensu? O mais simples é retornar a Bentham, visto que é traduzindo-o que Dumont emprega o termo em francês. Bentham promove o ascetismo à categoria filosófica para designar com ele um princípio aberrante, que corresponderia ao avesso do princípio da utilidade: este prescreve a maior felicidade à maioria enquanto o outro prescreve a maior infelicidade para a maioria! Formulado dessa maneira, o ascetismo é indefensável, mas ele testemunha, de alguma forma, a contrario a consistência do princípio de utilidade. $\mathrm{O}$ ascetismo é a contraprova do utilitarismo. Ora, este último é inteiramente suspenso por uma sorte de postulado herdado de Helvétius (e mais amplamente dos iluministas), a saber, que cada homem busca o prazer e foge da dor: "A natureza colocou a humanidade sob o governo de dois mestres soberanos, a dor e o 
Binoche, B.

prazer" ${ }^{16}$, essa é a abertura do capítulo $\mathrm{I}^{\mathbf{1 7}}$. Donde podemos concluir isto: $o$ ascetismo é introduzido em filosofia, negativamente, no contexto de uma antropologia materialista e hedonista, da qual a fortuna, tanto moral bem como política, será considerável.

E donde podemos ainda inferir a hipótese seguinte: toda uma posteridade anti-utilitarista fará grandes esforços para negar a "evidência" de que o indivíduo é governado pelo prazer e pela dor. A resistência teológica se torna reação filosófica. Muitos vão enxergar isso como a premissa "burguesa" por excelência. É por isso que será alvo tanto da tradição socialista quanto da tradição reacionária.

Do lado socialista, conhecemos a famosa fórmula por meio da qual Marx vê em Bentham o ideólogo do "inglês pequeno burguês"18. No entanto, Marx coloca sua crítica sobre o terreno das relações sociais e não sobre aquele da antropologia, ele faz pouco caso do ascetismo.

Por outro lado, toda uma tradição um tanto reacionária vai atacar essa premissa antropológica do utilitarismo. É essa tradição que nos interessa aqui, pois ela vai negar que o homem se governe pela busca do prazer e o medo da dor. É ela que vai reavaliar positivamente o mártir e o asceta contra o homem do cálculo racional, o comerciante: Chateaubriand publica Les martyrs em 1809 e, em 1844, La vie de Rancé, isto é, a biografia do fundador de La Trappe, - de Rancé, aliás, Schopenhauer reivindica frequentemente a herança. É uma reação reacionária ao hedonismo "burguês".

Ora, acerca dessa segunda perspectiva, duas opções são possíveis. É possível se contentar em afirmar que o homem é capaz de sacrificar o prazer e se expor ao sofrimento - é a valorização do "sacrifício" da qual o Cristo é a principal figura matriz. A este respeito, um dos textos mais reveladores é Eclaircissement sur les

16 Bentham, 2000, p. 14.

17 É por isso que os teólogos do século XVIII deploram que o profano não tenha tanto apreço pela mortificação (B. Groethuysen, Origines de l'esprit bourgeois en France, Paris, Gallimard, 1977, p.150).

18 Marx, 1993, p.683.

22 | Cad. Nietzsche, Guarulhos/Porto Seguro, v.39, n.2, p. 11-26, maio/agosto, 2018. 
Nietzsche, filho de seu tempo: a questão do ascetismo

sacrifices de Joseph de Maistre, cuja publicação póstuma aconteceu em 1821. Mas também é possível apagar mais sutilmente as fronteiras, negar a pretensa evidência da separação entre prazer e dor. Pode-se argumentar então que, na realidade, há prazer no sofrimento e viceversa. Esse entrecruzamento de afetos possui variantes múltiplas. $\mathrm{O}$ herói romântico experimenta uma certa volúpia na melancolia e, em 1802, René pode exclamar: "eu encontrei uma espécie de satisfação inesperada na plenitude de minha tristeza"19. Por outro lado, em 1870, o narrador de La vénus à la fourrure fará do sofrimento bem administrado uma arte do gozo e o "masoquista" se apresentará como a negação mais espetacular da antinomia sobre a qual estava sustentada a empreendimento utilitarista: é precisamente para gozar que é necessário sofrer! Séverin se revela, assim, como o irmão gêmeo perverso de René.

É preciso lembrar que, segundo Nietzsche, no caso específico do padre, "estamos diante de uma discordância que se quer ela própria discordante, que se apraz com ela mesma no sofrimento [welche sich selbst in diesem Leidengeniesst] [...]" (GM/GM, III, 11, KSA 5.361)? A esse respeito, temos a esclarecedora análise proposta por Ivan Soll num artigo de 1994 entitulado "Nietzsche on Cruelty, Asceticism, and the Failure of Hedonism " ${ }^{20}$ Soll havia notado que o interesse de Nietzsche pelo ascetismo devia ser entendido como uma objeção ao hedonismo utilitarista, isso porque a análise nietzschiana mostrava que a fronteira que separa o prazer do gozo é em realidade muito menos clara do que pretendia Bentham. Todavia, Soll havia confrontado Nietzsche diretamente com o utilitarismo sem levar em conta o que é evidenciado pela presente análise, a saber: por mais que o conceito de askesis possua uma venerável antiguidade, "o ascetismo" é um objeto filosófico próprio do século XIX.

19 Chateaubriand, 1969, p.140-141.

20 Ivan Soll, 1994, p.168-192.

Cad. Nietzsche, Guarulhos/Porto Seguro, v.39, n.2, p. 11-26, maio/agosto, 2018. 
Binoche, B.

Ora, é essa constatação, sem dúvida completamente paradoxal, que permite afirmar ainda o seguinte: quando Nietzsche, genealogista, combate a promoção schopenhauriana do ascetismo e também a de seus ascendentes religiosos, o próprio Nietzsche está cego acerca do contexto no qual ele mesmo está inserido. Ele não enxerga que todo o século XIX inventou o "ascetismo" contra o utilitarismo e que ele herda essa invenção. É nesse sentido que foi sugerido acima segundo paradoxo: Nietzsche apenas efetua a genealogia do "ideal ascético" porque ele ignora a história do "problema ascético". Isto é, o "ascetismo" enquanto objeto filosófico, que se impõe tanto a ele como também a seus contemporâneos.

É nesse sentido que ele é filho de seu tempo. Nietzsche pode muito bem pôr em pé de igualdade pessimismo e utilitarismo ${ }^{21}$, alegando que ambos superestimam a oposição do prazer e da dor em detrimento da potência. E ele também pode desvalorizar práticas ascéticas, interpretando-as como o sintoma de uma vontade de potência inibida, de uma vida doente. Mas a importância que o filósofo atribui ao tema, a própria valorização do problema ascético, é o sinal de seu pertencimento a uma conjuntura da qual ele é bastante tributário, mas que, contudo, ignora.

Talvez a perspicácia genealógica possuísse a falha inevitável da cegueira histórica: poderia Nietzsche ter destrinchado tão refinadamente os equívocos do ideal ascético se ele tivesse percebido de onde provinha seu interesse por este? O ideal é uma coisa, o conceito é outra coisa. E não é certo que possamos dar conta dos dois ao mesmo tempo...

$21 \mathrm{JGB} / \mathrm{BM}, \S 225$.

24 Cad. Nietzsche, Guarulhos/Porto Seguro, v.39, n.2, p. 11-26, maio/agosto, 2018. 
Nietzsche, filho de seu tempo: a questão do ascetismo

\begin{abstract}
The present article aims to analyze how does the nineteenth century historical-philosophical context has influenced Nietzsche's grasp of asceticism. For this purpose, it was necessary to take distance from Nietzsche's work to carry out a philological research on philosophical texts that dealt with the subject in the aforementioned century. This same research brought out the assumption that the term "asceticism" - in spite of having doctrinal, conceptual and etymological roots in Ancient and Medieval Ages - come up in European philosophy just in the nineteenth century. Throughout the argumentation it also has become evident how the interpretation and utilitarist usage of the notion of asceticism was essential to the elaboration of nietzschean criticism of ascetic ideal and practices.
\end{abstract}

Keywords: asceticism, nineteenth century, utilitarianism, Schopenhauer, Bentham

\title{
Referências bibliográficas
}

BENTHAM, Jeremy. An Introduction to the Principles of Morals and Legislation. Kitchener: Batoche Books, 2000.

BOSSUET, Instruction sur les états d'oraison. Paris: J. Anisson, 1697.

CONWAY, D. Nietzsche's On the Genealogy of Morals. Londres/New-York: Continuum International, 2008.

CHATEAUBRIAND, Euvres romanesques et voyages. Paris: Gallimard, 1969.

D’IORIO, P. Nietzsche à Sorrente. Paris: CNRS éditions, 2012.

FÉNELON. Euvres. Paris: Gallimard, t.I, 1983.

. Le gnostique de saint Clément d'Alexandrie. Paris-Orbey: Arfuyen, 2006.

FLEURY, C. Les mœurs des chrétiens, Paris: 1682.

GROETHUYSEN, B. Origines de l'esprit bourgeois en France. Paris: Gallimard, 1977.

HADOT, P. Exercices spirituels et philosophie antique. Paris: Albin Michel, 2002. 
Binoche, B.

HATTAB, L. J. Nietzsche's On the Genealogy of Morality. An Introduction. Cambridge: Cambridge UP, 2008

LEDUC-FAYETTE, D. Fénelon et l'amour de Dieu. Paris: PUF, 1996.

MARX. K. Le capital, trad. J.P. Lefebvre. Paris: PUF, 1993.

NIETZSCHE, F. Sämtliche Werke. Kritische Studienausgabe. G. Colli. e M. Montinari. Berlin: Walter de Gruyter, 1980.

Sämtliche Briefe: Kritische Studienausgabe (KSB). Berlin/ New York: Walter de Gruyter, 1986.

SCHACHT, R. (dir.), N. Genealogy, Morality. Essays on Nietzsche's Genalogy of Morals. Berkeley: Univ. of California Press, 1994.

SCHOPENHAUER, A. Le monde comme volonté et comme représentation. Trad. A. Burdeau. Paris: PUF, 1966.

SOLL, Ivan. "Nietzsche on Cruelty, Asceticism, and the Failure of Hedonism ". In: RICHARD Schacht (dir.). Nietzsche. Genealogy, Morality.Essays on Nietzsche’s Genalogy of Morals, Berkeley, Univ. of California Press, 1994, pp. 168-192.

STEGMAIER, Werner. Nietzsches "Genealogie der moral". Darmstadt: Wissenschaftliche Buchgesellschaft, 1994.

Artigo recebido para publicação em 18/02/2018 Artigo aceito para publicação em 12/05/2018

$26 \mid$ Cad. Nietzsche, Guarulhos/Porto Seguro, v.39, n.2, p. 11-26, maio/agosto, 2018. 